\title{
The Preventive Misconception: Experiences from CAPRISA 004
}

\author{
Rachael C. Dellar • Quarraisha Abdool Karim • Leila E. Mansoor • \\ Anneke Grobler · Hilton Humphries $\cdot$ Lise Werner $\cdot$ Fanelesibonge Ntombela • \\ Londiwe Luthuli $\cdot$ Salim S. Abdool Karim
}

Published online: 9 April 2014

(C) Springer Science+Business Media New York 2014

\begin{abstract}
Overestimating personal protection afforded by participation in a preventive trial, e.g. harboring a "preventive misconception" (PM), raises theoretical ethical concerns about the adequacy of the informed consent process, behavioral disinhibition, and adherence to prevention interventions. Data from the CAPRISA $0041 \%$ tenofovir gel trial were utilized to empirically evaluate these concerns. We found it necessary to re-think the current definition of PM during evaluation to distinguish between true misconception and reasonable inferences of protection based on increased access to evidence-based prevention interventions and/or clinical care. There was a significant association between PM and decreased condom use $(p<0.0001)$ and between PM and likelihood to present with an STI symptom $(p=0.023)$. There was, however, limited evidence in support of PM representing a lack of meaningful informed consent, or to suggest that it impacts adherence. Moreover, considering current insufficiencies in
\end{abstract}

R. C. Dellar · Q. Abdool Karim · L. E. Mansoor - A. Grobler · L. Werner · F. Ntombela · L. Luthuli · S. S. Abdool Karim Centre for the AIDS Programme of Research in South Africa (CAPRISA), Nelson R Mandela School of Medicine, University of KwaZulu-Natal, Durban, South Africa

Q. Abdool Karim ( $\square)$

CAPRISA, Doris Duke Medical Research Institute, Nelson R Mandela School of Medicine, University of KwaZulu-Natal, 2nd Floor, Congella, Private Bag X7, Durban 4013, South Africa e-mail: abdoolq2@ukzn.ac.za

Q. Abdool Karim · S. S. Abdool Karim

Department of Epidemiology, Mailman School of Public Health, Columbia University, New York, NY, USA

H. Humphries

Human Sciences Research Council (HSRC), Durban, South Africa female-initiated HIV prevention interventions, PM is perhaps of limited concern in microbicide trials.

Keywords Preventive misconception - Behavioral disinhibition - Adherence - Informed consent . Microbicides · HIV prevention

\section{Introduction}

Informed consent for clinical trials requires that participants fully understand the implications of research participation [1]. Importantly, misconceptions both positive and negative should be clarified, and the distinction between research and ancillary care provided clearly defined [2-8].

The implications of such misconception in HIV prevention trials (which typically involve healthy participants) have only recently begun to be considered, prompted in 2007 by the definition of the "preventive misconception" (PM) to describe "the overestimate in probability or level of personal protection that is afforded by being enrolled in a trial of a preventive intervention" [9].

In addition to theoretical implications of PM for the quality of the informed consent process, there are concerns that it may result in behavioral disinhibition, the phenomenon of increased risk taking behavior as a result of a perception of protection from a given disease or hazard $[10,11]$. Moreover, PM could result in increased engagement in high-risk sexual activities by participants who feel protected from HIV by trial participation [12, 13], placing themselves and their partners at increased risk of HIV infection.

A second, perhaps more complex, concern relates to the potential role for PM to affect adherence to interventions 
being evaluated and to motivate trial participation [12]. Given such factors influence trial outcomes [14, 15], researchers may need to measure PM in order to meaningfully interpret trial outcomes.

We assessed the extent of PM in South African female participants enrolled in the Centre for the AIDS Programme of Research in South Africa (CAPRISA) 004 tenofovir gel trial, and explored its relationship with informed consent, behavioral disinhibition, motivation for study participation and adherence to trial product.

\section{Methods}

\section{Study Setting and Participants}

This analysis uses data collected during CAPRISA 004 trial, a double-blind randomized controlled trial conducted between 2007 and 2010 which assessed the effectiveness and safety of coitally linked use of $1 \%$ tenofovir gel for the prevention of HIV acquisition in women [16]. In brief, a total of 889 sexually active, HIV-negative, 18-40 year old women who met all eligibility criteria and demonstrated adequate understanding of the trial participation (determined through a cognitive assessment) were enrolled from both an urban and a rural health clinic in KwaZuluNatal. After provision of written informed consent, women were assigned to either a tenofovir gel $(n=445)$ or placebo gel $(n=444)$ arm, and followed up monthly for 12-30 months. HIV serostatus, sexual behavior, trial product use and condom use were assessed monthly. At all visits, participants were provided with comprehensive HIV prevention services, including HIV testing, together with HIV pre- and post-test counselling (HCT), HIV risk reduction counselling, condom provision, and sexually transmitted infection (STI) treatment (if indicated). At trial exit, participants completed a structured, intervieweradministered questionnaire that assessed key indicators of $\mathrm{PM}$, including motivations for enrolment and perceptions of protection from trial participation. All women who acquired HIV during the study were excluded from analysis, as their perceptions of protection were considered to be biased by seroconversion.

\section{Ethics Statement}

The CAPRISA 004 trial (NCT00441298) was approved by the University of KwaZulu-Natal's Biomedical Research Ethics Committee (E111/06), Family Health International's Protection of Human Subjects Committee (\#9946), and the South African Medicines Control Council (\#20060835). No further ethical approval was required for this analysis.

\section{Data Analysis}

Perceptions of protection by trial participation from the relevant risk or disease have previously been used as proxy indicators for quantifying PM [9]. Based on this, we used the answers of participating women to an exit survey question that asked if they felt protected from infection with HIV by trial participation to explore PM in CAPRISA 004, taking perception of protection from HIV infection by trial participation as evidence for PM.

This classical definition of PM assumes that all rationale for perceived protection from HIV infection by trial participation are misconceptions and does not take into account any potentially evidence-based reasons for participants' perceptions of protection from HIV by trial participation, such as increased access to condoms. We therefore explored an expanded definition of PM which accounted for the rationale provided by women for their perceptions of protection or lack thereof in conjunction with the classical definition of PM. In the expanded definition, responses were differentiated based on perceptions of protection from HIV founded on use of trial product versus those founded on the use of evidence-based prevention methods provided as part of ancillary care received that included HIV testing and counselling, STI treatment or use of male and/or female condoms.

The reasons participants gave for perceptions of protection or non-protection from HIV by trial participation were classed into 12 distinct categories: (1) felt protected from HIV by trial participation because of provision of trial product; (2) felt protected from HIV by trial participation because provided with trial product and condoms, HCT, STI management or risk reduction counselling services; (3) felt protected from HIV by trial participation because provided with condoms or encouraged to use condoms; (4) felt protected from HIV by trial participation because provided with HCT, STI management or risk reduction counselling services; (5) felt protected from HIV by trial participation because remained HIV negative during course of trial; (6) felt protected from HIV by trial participation but response ambiguous; (7) felt protected from HIV by trial participation but no reasons given; (8) did not feel protected from HIV by trial participation because trial product still experimental; (9) did not feel protected from HIV by trial participation because perceptions of protection depended on factors independent of the trial; (10) did not feel protected from HIV by trial participation because did not know which arm of the study enrolled in; (11) did not feel protected from HIV by trial participation but ambiguous response given; (12) did not feel protected from HIV by trial participation but no reasons given. Classifications were performed by two researchers independently to minimize subjectivity. Any 
Fig. 1 Quantifying PM in CAPRISA 004

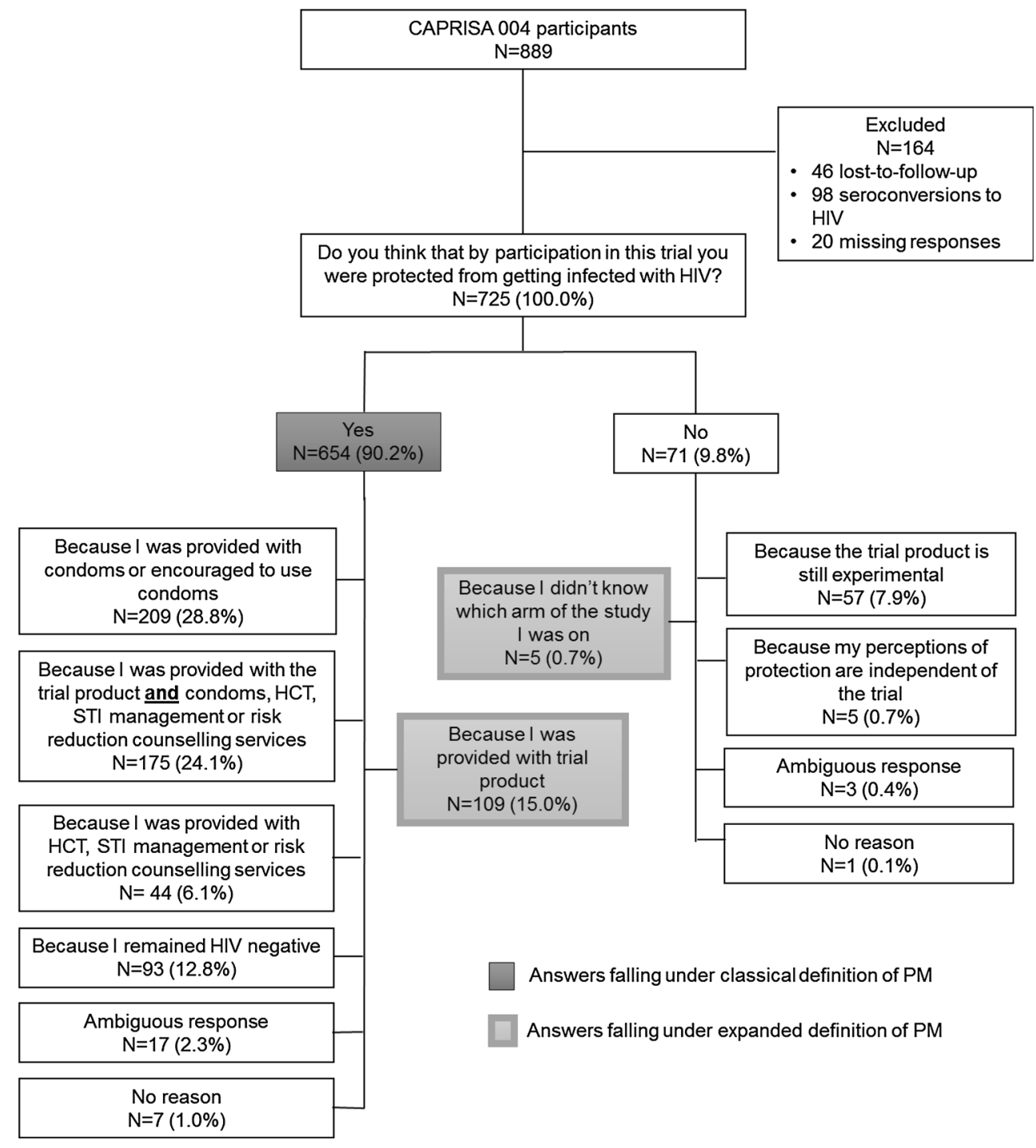

discrepancies between classifications were discussed and resolved with a third party if required.

Correlations between evidence for a PM (by both definitions) and demographic, clinical and behavioral characteristics were tested using Fischer's exact tests for categorical data, or by independent t-tests (equal variances not assumed) for continuous data. Adherence was calculated as the proportion of sex acts covered by two doses of trial product, which was determined by monthly applicator count and selfreported coital frequency, as previously described [16]. A number of variables were explored as indicators of behavioral disinhibition including mean monthly number of sex acts, mean monthly number of sexual partners, STI symptoms, partner concurrency, partner change, and condom use. For condom use, Cochran-Armitage trend analysis was performed on reported frequency of condom use (always, most, sometimes, seldom or never). All data were analysed in SPSS version 21 (SPSS, IBM, New York, USA).

\section{Results}

Socio-demographic and Behavioral Characteristics of Participants at Enrolment

The responses of 725/889 (81.6\%) trial participants were included in this study. Reasons for participant exclusion in this analysis were loss-to-follow up $(n=46)$, HIV seroconversion ( $\mathrm{n}=98$ ) (which was likely to bias perceptions of protection) and missing responses $(n=20)$ (Fig. 1).

The demographic and behavioral characteristics of the cohort overall and stratified by the classical and expanded definitions of PM are presented in Table 1. The majority of participants were from the rural site $(69.9 \%)$, were in stable relationships $(92.8 \%)$, had not completed high school $(59.5 \%)$ and had limited or no income $(92.4 \%)$. The mean age of participants was 23.8 years, and the mean number of lifetime sexual partners was 2.9. 
Table 1 Characterising women with PM

\begin{tabular}{|c|c|c|c|c|c|c|c|c|}
\hline & \multicolumn{4}{|c|}{$\begin{array}{l}\text { Perception of protection from HIV by participation } \\
\text { in trial }\end{array}$} & \multicolumn{4}{|c|}{$\begin{array}{l}\text { Perception of protection from HIV by trial product } \\
\text { alone }\end{array}$} \\
\hline & $\begin{array}{l}\text { Total } \\
(\mathrm{N}=725)\end{array}$ & $\begin{array}{l}\text { Yes } \\
(\mathrm{N}=654)\end{array}$ & $\begin{array}{l}\text { No } \\
(\mathrm{N}=71)\end{array}$ & $\begin{array}{l}p \text { - } \\
\text { Value }\end{array}$ & $\begin{array}{l}\text { Total } \\
(\mathrm{N}=697)^{\mathrm{a}}\end{array}$ & $\begin{array}{l}\text { Yes } \\
(\mathrm{N}=114)\end{array}$ & $\begin{array}{l}\text { No } \\
(\mathrm{N}=583)\end{array}$ & $\begin{array}{l}p- \\
\text { Value }\end{array}$ \\
\hline \multicolumn{9}{|l|}{ Demographics } \\
\hline Rural \% (n) & $69.9(507)$ & $72.8(476)$ & $43.7(31)$ & $<0.001$ & $69.4(484)$ & $66.7(76)$ & $70.0(408)$ & 0.505 \\
\hline Mean age (years) (SD) & $23.8(5.1)$ & $23.8(5.2)$ & $24.1(4.7)$ & 0.678 & $23.8(5.2)$ & $23.8(5.6)$ & $23.9(5.1)$ & 0.815 \\
\hline \multicolumn{9}{|l|}{ Education } \\
\hline Completed high school \% (n) & $41.4(300)$ & $40.5(265)$ & $49.3(35)$ & 0.164 & $41.0(286)$ & $43.9(50)$ & $40.5(236)$ & 0.533 \\
\hline Completed primary school \% (n) & $96.6(700)$ & $96.2(629)$ & $100.0(71)$ & 0.160 & $96.6(673)$ & $98.2(112)$ & $96.2(561)$ & 0.403 \\
\hline \multicolumn{9}{|l|}{ Relationship status } \\
\hline Married \% (n) & $5.7(41)$ & $5.8(38)$ & $4.2(3)$ & 0.788 & $5.6(39)$ & $8.8(10)$ & $5.0(29)$ & 0.118 \\
\hline Stable relationship \% (n) & $92.8(673)$ & $92.5(605)$ & $95.8(68)$ & 0.466 & $92.8(647)$ & $90.4(103)$ & $93.3(544)$ & 0.319 \\
\hline Casual relationship \% (n) & $5.1(37)$ & $5.0(33)$ & $5.6(4)$ & 0.776 & $5.2(36)$ & $7.0(8)$ & $4.8(28)$ & 0.353 \\
\hline \multicolumn{9}{|l|}{ Income } \\
\hline Own income \% (n) & $89.1(646)$ & $89.0(582)$ & $90.1(64)$ & 1.000 & $89.1(621)$ & $86.8(99)$ & $89.5(522)$ & 0.412 \\
\hline Income $<\mathrm{R} 1000^{\mathrm{b}}$ per month $\%(\mathrm{n})$ & $92.4(670)$ & 93.4 (611) & 83.1 (59) & 0.007 & $92.1(642)$ & $87.7(100)$ & $93.0(542)$ & 0.084 \\
\hline \multicolumn{9}{|l|}{ Baseline sexual characteristics } \\
\hline $\begin{array}{l}\text { Mean age (years) at sexual debut } \\
\text { (SD) }\end{array}$ & $17.4(2.1)$ & $17.4(2.1)$ & $17.7(1.8)$ & 0.222 & $17.4(2.0)$ & $17.4(1.8)$ & $17.4(2.1)$ & 0.769 \\
\hline $\begin{array}{l}\text { Mean lifetime number of sexual } \\
\text { partners (SD) }\end{array}$ & $2.9(8.5)$ & $2.9(8.9)$ & $2.8(3.1)$ & 0.892 & $2.9(8.7)$ & $5.16(20.5)$ & $2.5(2.7)$ & 0.003 \\
\hline
\end{tabular}

Socio-demographics and behavioral characteristics of cohort at enrolment stratified by classical and expanded definitions of PM

a 28 responses were excluded as a result of either ambiguity in response $(\mathrm{n}=20)$ or not giving reasons for perception $(\mathrm{n}=8)$

${ }^{\mathrm{b}} \mathrm{R} 1000 \approx \mathrm{US} \$ 92$

\section{PM and Perception of HIV Risk}

The majority $(90.2 \% ; 654 / 725)$ of women indicated that they thought participating in the trial protected them from HIV acquisition. Women who perceived themselves to be protected from HIV infection by trial participation were significantly more likely to be rural $(p<0.001)$ and earn less $(p=0.007)$ compared to women who did not feel protected. Women who perceived themselves to be protected from HIV infection by use of the trial product (e.g. yielding a PM by the expanded definition) were significantly more likely to have a higher number of lifetime sexual partners compared to other women in the trial $(p=0.003)$.

Participants' rationales for perceptions of protection or non-protection are presented in Fig. 1. The data suggests that use of the classical definition could be inflating the occurrence of PM if the rationale for the response is not considered. About a third, $(32.0 \% ; \mathrm{n}=209)$ of women who felt protected felt so because of increased access to condoms, whilst $6.7 \%(\mathrm{n}=44)$ felt protected because of access to other forms of ancillary care such as risk reduction counselling. Examples of such evidence-based perceptions of protection are included in statements below:

[I felt protected from HIV infection by participation in the trial] by consistent condom use that I wasn't used to before I joined

[I felt protected from HIV infection by participation in the trial] by attending HIV counselling and testing...negative results were making me proud and feel motivated to use condoms.

A further $14.2 \%(\mathrm{n}=93)$ of women who felt protected by trial participation indicated that their own or their peers' continued HIV negative status suggested to them that the trial product offered some degree of protection as the high HIV incidence rates in this setting placed them at high risk of acquiring HIV.

The perception of protection offered by use of the trial product was mentioned by $43.4 \%(n=284)$ of women who felt protected by trial participation. However, of these 284 women only $38.4 \%(\mathrm{n}=109)$ felt protected solely from the use of trial product (the others also including increased access to condoms and education as important factors in prevention). Of note, six participants who felt 
Table 2 Implications of PM for informed consent

\begin{tabular}{|c|c|c|c|c|c|c|c|c|}
\hline & \multicolumn{4}{|c|}{$\begin{array}{l}\text { Perception of protection from HIV by participation } \\
\text { in trial }\end{array}$} & \multicolumn{4}{|c|}{$\begin{array}{l}\text { Perception of protection from HIV by trial product } \\
\text { alone }\end{array}$} \\
\hline & $\begin{array}{l}\text { Total } \\
(\mathrm{N}=725)\end{array}$ & $\begin{array}{l}\text { Yes } \\
(\mathrm{N}=654)\end{array}$ & $\begin{array}{l}\text { No } \\
(\mathrm{N}=71)\end{array}$ & $\begin{array}{l}p- \\
\text { Value }^{*}\end{array}$ & $\begin{array}{l}\text { Total } \\
(\mathrm{N}=697)^{\mathrm{a}}\end{array}$ & $\begin{array}{l}\text { Yes } \\
(\mathrm{N}=114)\end{array}$ & $\begin{array}{l}\text { No } \\
(\mathrm{N}=583)\end{array}$ & Value $^{*}$ \\
\hline \multicolumn{9}{|l|}{ Arm perception } \\
\hline Thought tenofovir \% (n) & $18.8(136)$ & $19.4(127)$ & $12.7(9)$ & 0.201 & $18.5(129)$ & $21.1(24)$ & $18.0(105)$ & 0.431 \\
\hline Didn’t know \% (n) & $80.0(580)$ & $79.7(521)$ & $83.1(59)$ & 0.639 & $80.2(559)$ & $77.2(88)$ & $80.8(471)$ & 0.371 \\
\hline \multicolumn{9}{|l|}{ Trial understanding } \\
\hline Trial language understood \% (n) & $99.3(720)$ & $99.2(649)$ & $100.0(71)$ & 1.000 & $99.3(692)$ & $100.0(114)$ & $99.1(578)$ & 1.000 \\
\hline $\begin{array}{l}\text { Correct identification of study } \\
\text { purpose } \%(\mathrm{n})\end{array}$ & 97.7 (708) & $97.4(637)$ & $100.0(71)$ & 0.397 & $97.6(680)$ & $99.1(113)$ & $97.3(567)$ & 0.333 \\
\hline Felt had enough information $\%$ (n) & $99.2(719)$ & $99.2(649)$ & $98.6(70)$ & 0.462 & $99.3(692)$ & $98.2(112)$ & $99.5(580)$ & 0.190 \\
\hline \multicolumn{9}{|l|}{ Motivation for participation } \\
\hline Own protection $\%(\mathrm{n})$ & $54.9(398)$ & $56.9(372)$ & $36.6(26)$ & 0.002 & $55.4(386)$ & $44.7(51)$ & $57.5(335)$ & 0.014 \\
\hline $\begin{array}{l}\text { Stop epidemic/help Community \% } \\
\text { (n) }\end{array}$ & $56.3(408)$ & $57.5(376)$ & $45.1(32)$ & 0.260 & $56.1(391)$ & $58.8(67)$ & $55.6(324)$ & 0.583 \\
\hline
\end{tabular}

Key indicators of informed consent stratified by classical and expanded definitions of PM

${ }^{a}$ Twenty-eight responses were excluded as a result of either ambiguity in response $(\mathrm{n}=20)$ or not giving reasons for perception $(\mathrm{n}=8)$

protected by trial product alone attributed their faith in the product to the fact that it contains a known antiretroviral drug used to treat HIV.

Additionally, some evidence of PM was identified in those participants who did not feel protected by trial participation, with $7.0 \%(\mathrm{n}=5)$ of these women indicating feelings of non-protection because of a perceived assignment to the placebo gel arm: thus suggesting that if they perceived assignment to the active trial product arm that they would feel protected from HIV.

\section{PM and Informed Consent}

To explore the implications of PM for meaningful informed consent, trial understanding and motivations for participation were investigated (Table 2).

General knowledge about the trial was high, with $97.7 \%$ of participants correctly identifying the purpose to test tenofovir gel for HIV prevention. Reported understanding of the trial language used during the informed consent procedures was also high $(99.3 \%)$ and the majority $(99.2 \%)$ of participants felt they had received enough information about the trial during these procedures. To further probe understanding of key trial concepts, participants were asked about which arm of the trial they thought they were on; whilst most 'correctly' did not know owing to their understanding of the randomization process, $18.8 \%$ of women believed they were in the tenofovir arm and $1.2 \%$ believed they were in the placebo arm. No associations were found between this or any other indicator of trial understanding and either definition of PM.
Motivations for trial participation were investigated as proxy indicators for PM. Those with a perception of protection from trial participation were more likely to cite their own protection as a motivation for trial participation compared to those who did not feel protected by trial participation $(p=0.001)$. Those women who felt protected by trial product alone were also significantly more likely to cite their own protection as a motivator to join the trial $(p=0.014)$. However, a significant proportion of women who cited their own protection as a motivator for enrolment also cited altruistic motivations for joining the trial such as stopping the HIV epidemic or helping the community.

PM, Behavioral Disinhibition and Adherence

No evidence for an association between PM and indicators of behavioral disinhibition was observed using the classical definition of perception of protection from HIV by trial participation (Table 3). However, using the expanded definition, reports of always using a condom were significantly lower in those participants who felt protected from HIV by trial product use only $(p=0.001)$; conversely, reports of never using a condom were higher in this group $(p=0.003)$. Those women who felt protected from HIV by use of the trial product were also significantly more likely to have presented with an STI symptom during a clinic visit compared to other women $(p=0.023)$. No associations were found between adherence and either measurement of PM. 
Table 3 Implications of PM for behavioral disinhibtion and adherence

\begin{tabular}{|c|c|c|c|c|c|c|c|c|}
\hline & \multicolumn{4}{|c|}{$\begin{array}{l}\text { Perception of protection from HIV by participation } \\
\text { in trial }\end{array}$} & \multicolumn{4}{|c|}{$\begin{array}{l}\text { Perception of protection from HIV by trial product } \\
\text { alone }\end{array}$} \\
\hline & $\begin{array}{l}\text { Total } \\
(\mathrm{N}=725)\end{array}$ & $\begin{array}{l}\text { Yes } \\
(\mathrm{N}=654)\end{array}$ & $\begin{array}{l}\text { No } \\
(\mathrm{N}=71)\end{array}$ & $\begin{array}{l}p- \\
\text { Value }\end{array}$ & $\begin{array}{l}\text { Total } \\
(\mathrm{N}=697)^{\mathrm{a}}\end{array}$ & $\begin{array}{l}\text { Yes } \\
(\mathrm{N}=114)\end{array}$ & $\begin{array}{l}\text { No } \\
(\mathrm{N}=583)\end{array}$ & $p$-Value \\
\hline $\begin{array}{l}\text { Mean number of sex acts monthly } \\
\text { (SD) }\end{array}$ & $4.8(3.3)$ & $4.7(3.2)$ & $5.3(4)$ & 0.143 & $4.8(3.3)$ & $5.1(4.4)$ & $4.7(3.1)$ & 0.402 \\
\hline $\begin{array}{l}\text { Concordance at any point in } \\
\text { study } \%(\mathrm{n})\end{array}$ & $2.6(19)$ & $2.6(17)$ & $2.8(2)$ & 0.709 & $2.6(18)$ & $3.5(4)$ & $2.4(14)$ & 0.516 \\
\hline STI symptom at any visit \% (n) & $66.5(482)$ & $66.1(432)$ & $70.4(50)$ & 0.510 & $66.3(462)$ & $75.4(86)$ & $64.5(376)$ & 0.023 \\
\hline Partner concordance \% (n) & $35.0(254)$ & $33.8(221)$ & $46.5(33)$ & 0.037 & $35.0(244)$ & $32.5(37)$ & 35.5 (207) & 0.592 \\
\hline $\begin{array}{l}\text { New partner at any point in study } \\
\%(\mathrm{n})\end{array}$ & $7.0(51)$ & $7.0(46)$ & $7.0(5)$ & 1.000 & $7.0(49)$ & $9.6(11)$ & $6.5(38)$ & 0.231 \\
\hline $\begin{array}{l}\text { Mean monthly median adherence } \\
\text { (SD) }\end{array}$ & $70.3(25.1)$ & $70.4(24.9)$ & $68.9(26.2)$ & 0.628 & $70.2(25.1)$ & $66.9(25)$ & $70.8(25)$ & 0.133 \\
\hline \multicolumn{9}{|l|}{ Condom use } \\
\hline Always \% (n) & $58.6(425)$ & 41.7 (273) & $38.0(27)$ & 0.319 & 41.5 (289) & $26.3(30)$ & $44.4(259)$ & $<0.001$ \\
\hline Sometimes \% (n) & $14.1(102)$ & $14.2(93)$ & $12.7(9)$ & 0.444 & $14.3(100)$ & $16.7(19)$ & $13.9(81)$ & 0.465 \\
\hline Never \% (n) & $5.7(41)$ & $6.0(39)$ & $2.8(2)$ & 0.416 & $5.5(38)$ & $11.4(13)$ & $4.3(25)$ & 0.005 \\
\hline Trend analysis ${ }^{\mathrm{b}}$ & - & - & - & 0.890 & - & - & - & $<0.0001$ \\
\hline
\end{tabular}

Key indicators of behavioral disinhibition and adherence stratified by classical and expanded definitions of PM

${ }^{a}$ Twenty-eight responses were excluded as a result of either ambiguity in response $(n=20)$ or not giving reasons for perception $(n=8)$

${ }^{\mathrm{b}}$ Cochran-Armitage trend analysis performed on reports of condom use (always, most, sometimes, seldom or never) in last four weeks of study

\section{Discussion}

To our knowledge this is the first empirical evaluation of the ethical concerns relating to PM. We found significant associations between PM and condom use and PM and STI symptoms, and some evidence that PM motivates trial participation. However, we found limited evidence to justify concerns that high levels of PM represent a lack of meaningful informed consent.

Importantly, using an expanded definition of PM we have been able to distinguish between true misconceptions and reasonable inference. Moreover, over $80 \%$ of women who might have been considered to harbor a PM by stating that they felt protected from HIV by trial participation had reasonable and evidence-based justifications for this perception. We also found evidence for PM in those women who did not feel protected, highlighting limitations in the current definition of PM. Thus, whilst we recognize that consistent definitions of key ethical parameters are necessary to ensure good practice and facilitate comparisons between trials, we believe that the expansion of the current definition to take into account the context of the trial and the rationale for a response will provide a more meaningful interpretation of participant decisions and actions.

With respect to behavioral disinhibition this expanded definition has enabled us to gain a nuanced insight into reduced condom use in women who believed they were protected from HIV by the trial product. Given that such behavioral disinhibition may pose a serious risk of harm to the trial participant, and potentially to their partners, identification of the basis for this misconception, as well as continued risk reduction counselling, are critical.

Previous literature on PM suggest that its minimization requires understanding of key research concepts in order to ensure consent is meaningful [13]. Whilst we found some evidence of misunderstanding in terms of randomization and a tendency of participants to overestimate the probability of assignment to the intervention, general understanding of the trial was high and no evidence suggested a correlation between PM and any misunderstanding. Perhaps, as has previously been suggested, even in the context of thorough informed consent procedures, there is simply a degree of 'wishful thinking' within some trial participants that is of less ethical concern than more concrete misconceptions [12]. Furthermore, although we did find some evidence that PM may serve as a motivator for trial participation, such evidence was limited and other altruistic motivators were typically more common. Further work is required to confirm such an association.

In conclusion, we believe it is necessary to make distinctions between what is potentially behavioural disinhibition inducing, harmful misconception, and what is evidence-based interference or 'wishful thinking' when quantifying and evaluating PM in preventive trials. Such distinctions should facilitate more in-depth explorations of potential causes and routes to overcome the potentially numerous harmful implications of the former and help to 
ensure the highest ethical standards in prevention trials whilst maintaining respect for the knowledge base of trial participants even in resource constrained settings.

Acknowledgments We pay tribute to the women who participated in this trial; their dedication and commitment made this study possible. The CAPRISA 004 Tenofovir Gel trial is supported by the Centre for the AIDS Program of Research in South Africa (CAPRISA), the United States Agency for International Development (USAID), Family Health International (FHI) (cooperative agreement \# GPO-A-00-05-00022-00, contract \# 132119), and LIFElab, a biotechnology center of the South African Department of Science and Technology. Support from CONRAD for the product manufacturing and packaging as well as support from Gilead Sciences for the Tenofovir used in the production of gel is gratefully acknowledged. We thank the US National Institutes for Health's Comprehensive International Program of Research on AIDS (CIPRA Grant \# AI51794) and the Columbia University-Southern African Fogarty AIDS International Training and Research Programme (AITRP Grant \# D43TW00231) for the research infrastructure and training that made this trial possible.

\section{References}

1. Beauchamp TL. Methods and principles in biomedical ethics. J Med Ethics. 2003;29(5):269-74.

2. Appelbaum PS, Roth LH, Lidz C. The therapeutic misconception: informed consent in psychiatric research. Int $\mathrm{J}$ Law Psychiatry. 1982;5(3-4):319-29.

3. Appelbaum PS, Roth LH, Lidz CW, Benson P, Winslade W. False hopes and best data: consent to research and the therapeutic misconception. Hastings Cent Rep. 1987;17(2):20-4.

4. Brody BA, McCullough LB, Sharp RR. Consensus and controversy in clinical research ethics. JAMA. 2005;294(11):1411-4.
5. Crigger BJ, National Bioethics Advisory Commission. National Bioethics Advisory Commission Report: ethical and policy issues in international research. IRB. 2001;23(4):9-12.

6. Dresser R. The ubiquity and utility of the therapeutic misconception. Soc Philos Policy. 2002;19(2):271-94.

7. Henderson GE, Churchill LR, Davis AM, et al. Clinical trials and medical care: defining the therapeutic misconception. PLoS Med. 2007;4(11):e324

8. Lidz CW, Appelbaum PS. The therapeutic misconception: problems and solutions. Med Care. 2002;40(9 Suppl):V55-63.

9. Simon AE, Wu AW, Lavori PW, Sugarman J. Preventive misconception: its nature, presence, and ethical implications for research. Am J Prev Med. 2007;32(5):370-4.

10. Pinkerton SD. Sexual risk compensation and HIV/STD transmission: empirical evidence and theoretical considerations. Risk Anal. 2001;21(4):727-36.

11. Richens J, Imrie J, Copas A. Condoms and seat belts: the parallels and the lessons. Lancet. 2000;355(9201):400-3.

12. Woodsong C, Alleman P, Musara P, et al. Preventive misconception as a motivation for participation and adherence in microbicide trials: evidence from female participants and male partners in Malawi and Zimbabwe. AIDS Behav. 2012;16(3):785-90.

13. Ott MA, Alexander AB, Lally M, Steever JB, Zimet GD. Adolescent Medicine Trials Network (ATN) for HIV/AIDS Interventions. Preventive misconception and adolescents' knowledge about HIV vaccine trials. J Med Ethics. 2013;39(12):765-71.

14. Tolley EE, Harrison PF, Goetghebeur E, et al. Adherence and its measurement in phase $2 / 3$ microbicide trials. AIDS Behav. 2010;14(5):1124-36.

15. Woodsong C, MacQueen K, Amico KR, et al. Microbicide clinical trial adherence: insights for introduction. J Int AIDS Soc. 2013;16:18505.

16. Abdool Karim Q, Abdool Karim SS, Frohlich JA, et al. Effectiveness and safety of tenofovir gel, an antiretroviral microbicide, for the prevention of HIV infection in women. Science. 2010;329(5996):1168-74. 